
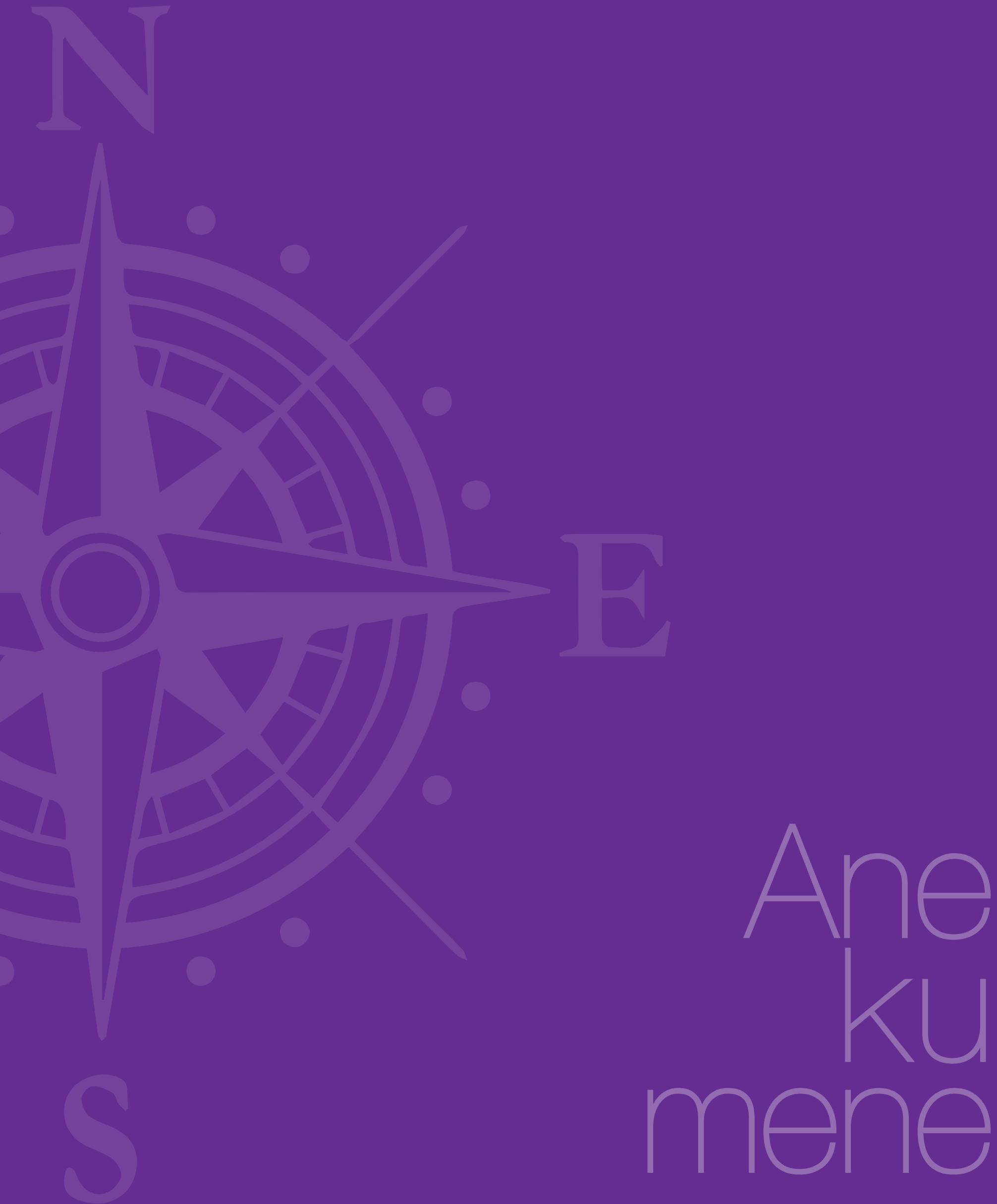


\section{Rede Dialógica: Ensinar e aprender Geografia na América Latina}

\section{Red dialógica: Enseñar y aprender Geografía en América Latina}

Dialogic Network: Teaching and Learning Geography in Latin America

Adriana Maria Andreis ${ }^{1}$

Cláudia Eliane Ilgenfritz Toso²

\section{Resumo}

Para pensarmos sobre os desafios de ensinar e aprender Geografia na América Latina, apresentamos uma a noção de rede, argumentada como possibilidade dialógica. Considerando que a reflexão acerca dos processos educativos pode ser enriquecida se o debate envolver um foco comum e uma discussão que acolhe a diversidade, neste artigo, comentamos sobre a Rede Latino-Americana de investigadores em Didática da Geografia (Redladgeo) e resenhamos a publicação do livro Didáctica de la geografia: prácticas escolares y formación de professores. Metodologicamente esse ensaio teórico resulta das nossas vivências como professoras-pesquisadoras participantes do grupo, e com referenciais teóricos da Educação, Geografia, História, Ciências Sociais e Filosofia, entre outros. Organizamos o texto em partes nas quais analisamos a tessitura de uma rede, e argumentamos em favor do escrever como modo melhor para pensar, exemplificando por meio da publicação da obra do grupo. Essas proposições nos permitem afirmar a potência dialética-dialógica da rede como possibilidade pedagógica, no âmbito dos processos de ensinar e aprender Geografia.

\section{Palavras-chave}

Dialética-dialógica; escrever e pensar; didática

1 Professora de Geografia na Universidade Federal da Fronteira Sul-UFFS, campus Chapecó/SC

2 Doutoranda do Programa de Pós-Graduação em Educação nas Ciências da Universidade Regional do Noroeste do Estado do Rio Grande do Sul-Unijui; Bolsista Capes/Prosup. 


\section{Palabras clave}

Dialéctica-dialógica; escribir y pensar; didáctica

\title{
Resumen
}

Con el objetivo de reflexionar sobre los desafíos de la enseñanza y aprendizaje de la Geografía en América Latina, ofrecemos una noción de red que proponemos como posibilidad dialógica. Convencidos que la reflexión sobre los procesos educativos se puede enriquecer si el debate involucra un enfoque común y una discusión que da la bienvenida a la diversidad, en este artículo, hacemos una análisis de la Red Latinoamericana de Investigadores de la Didáctica de la Geografía (Redladgeo) y reseñamos la publicación del libro Didáctica de la geografia: prácticas escolares y formación de los profesores. Metodológicamente este estudio teórico resulta de nuestras experiencias como profesores-investigadores participantes en el grupo, y de la investigación de teóricos de la educación, la geografía, la historia, las ciencias sociales y la filosofía, entre otros. Organizamos el texto en partes en las que se analizan la tesitura de una red, y defendemos la escritura como la mejor manera de pensar, como se ejemplifica a través de la publicación del libro de la red. Estas proposiciones permiten afirmar el poder de la dialéctica-dialógica de la red como una oportunidad pedagógica, en los procesos de enseñanza y aprendizaje de la Geografía.

\section{Abstract}

\author{
Keywords \\ Dialectics-dialogics; \\ writing and thinking; \\ didactics
}

To think about the challenges of teaching and learning Geography in Latin America, we present a notion of network, argued as a dialogic possibility. Knowing that the reflection on educational processes can be enriched if the debate involves a common approach and a discussion that welcomes diversity, in this article, we comment on the Latin American Network of Researchers on the Teaching of Geography (in Spanish, Redladgeo). We also review the publication of the book Didactics of Geography: School Practices and Teacher Training. Methodologically, this theoretical study is a result of our experiences as teachers-researchers participating in the group, and theoretical frameworks by experts in education, geography, history, social sciences and philosophy among others. The text is organized into parts where we analyze the composition of a network, and support writing as the best way to think, as exemplified through the publication of the group's work. These propositions allow us to state the potential of the dialectics-dialogics of the network as a pedagogical opportunity, in the processes of teaching and learning geography. 
Tecendo a Manhã $\tilde{a}^{3}$ João Cabral de Melo Neto Um galo sozinho não tece uma manhã: ele precisará sempre de outros galos. De um que apanhe esse grito que ele e o lance a outro; de um outro galo que apanhe o grito de um galo antes e o lance a outro; e de outros galos que com muitos outros galos se cruzem os fios de sol de seus gritos de galo, para que a manhã, desde uma teia tênue, se vá tecendo, entre todos os galos.

E se encorpando em tela, entre todos, se erguendo tenda, onde entrem todos, se entretendendo para todos, no toldo (a manhã) que plana livre de armação.

A manhã, toldo de um tecido tão aéreo que, tecido, se eleva por si: luz balão.

o Sol está o tempo todo nascendo em algum lugar. Sempre, para alguém é amanhecer, é o morrer de uma noite, outro dia, único. o Sol está o tempo todo se pondo em algum lugar. Sempre para alguém é entardecer, o morrer de um dia, outra noite, diferente. Tudo ao mesmo tempo, agora. Término e começo, vida e morte, inerente ao viver. (Andreis, 2014)

\section{A tessitura de uma rede}

As originalidades produto-produtoras de cada lugar são tecidas em elos, com fios compostos de diferentes linguagens, refratando e criando outras ideias e processos. Uma dinâmica aberta, complexificadora de redes de elaborações sempre provisórias, sempre começo. Pouco se sabe acerca dos porquês do cantar dos galos em redes, que nunca terminam, porque nunca começam, visto que está sempre amanhecendo em algum lugar, ou seja, está sempre começando o hoje. Sabemos, porém, que o amanhã é sempre o hoje de algum lugar, e que cada enunciado é um grito singular, que diz de um mundo único, mas que é sempre para e com o outro.

Tecendo o hoje, as redes são composições de tramas em dois sentidos: primeiro, porque são um movimento dotado de intencionalidade, $\mathrm{e}$ segundo, porque se constituem como elos propositados, preocupados acentuar o tensionamento de alguma questão. Urdiduras de relações de entrecruzamento, as vinculações concretas e abstratas, visíveis e invisíveis, são permanentemente atualizadas. Na rede, alguns elos são

3 Disponível em: http://www.jornaldepoesia.jor.br/joao02.html. Acesso em: 23 out. 2014. fortalecidos devido às pretensões e ideias que os aproximam. É com esse sentido dialógico de elos propositados, que se constitui a Rede Latino-Americana de investigadores em Didática da Geografia - Redladgeo, conjugando objetivos de reflexão sistemática acerca dos processos de ensinar e aprender Geografia.

A Redladgeo foi constituída a partir de inquietudes presentes no XI Encontro de Geógrafos da América Latina-EGAL, realizado na cidade de Bogotá, Colômbia, entre 26 e 30 de março de 2007. Inclui professores e pesquisadores interessados nas temáticas que envolvem a Didática da Geografia. A rede envolve um cenário acadêmico, que fortemente aposta em processos de inovação do/no ensino de Geografia e sua didática, em contextos escolares formais e não formais. Portanto, trata-se de um convite ao debate, aos interessados na docência em Geografia e das Ciências Sociais em geral, para que encontrem um espaço para a reflexão e aporte à Geografia escolar, nos atuais contextos sócio-territoriais. Trata-se de um espaço acadêmico, que promove processos de investigação e inovação no ensino de Geografia em contextos escolares de todos os níveis e sistemas educativos da América Latina. O interesse é, também, aportar elementos teóricos, conceituais e metodológicos, que possam dialogar com a formação de professores ${ }^{4}$.

A rede visa, especialmente, refletir sobre a importância, desafios e possibilidades implicados na construção de redes interinstitucionais de diálogo sobre o ensino-aprendizagem envolvendo noções espaço-temporais. Os debates permanentes, que acontecem (presencialmente e não presencialmente) entre diferentes grupos e pesquisadores dos países latino-americanos, confluíram até esse momento, em três encontros gerais: I Colóquio realizado em São Paulo (Brasil) em 2010, || Colóquio, realizado em Santiago do Chile (Chile) em 2012, e o III Colóquio, realizado em Buenos Aires (Argentina) em 2014. Ao encontro da tessitura da rede, está programado o IV Colóquio para o ano de 2016, em Bogotá (Colômbia) ${ }^{5}$.

A realização de colóquios expressa a pretensão da rede como lugar de reflexão e debate, entre diferentes perspectivas de ensino e investigação. Assim, o encontro permite que sejam analisadas questões relacionadas à didática, no qual todos os participantes podem se envolver em todos os debates e evitando que se configure em mera apresentação de trabalhos sem tempo às análises.

Para refletir sobre o projeto, elaboramos uma figura para auxiliar na compreensão da noção de rede. Constituímo-la com a pretensão de configurá-la como dialética-dialógica (Bulavka e Busgalin, 2005), que a seguir, imprimimos.

4 Informações disponíveis em: http://www.geopaideia.com/?page_id=6. Acesso em: 27 out. 2014

5 Informações disponibilizadas na $4^{a}$ Circular do III Coloquio Internacional de Investigadores en Didáctica de la Geografía, Buenos Aires, 29 de setembro de 2014. 
Figura 1 Rede Dialógica-Didática em Geografia (Geografia, História, Ciências Sociais)

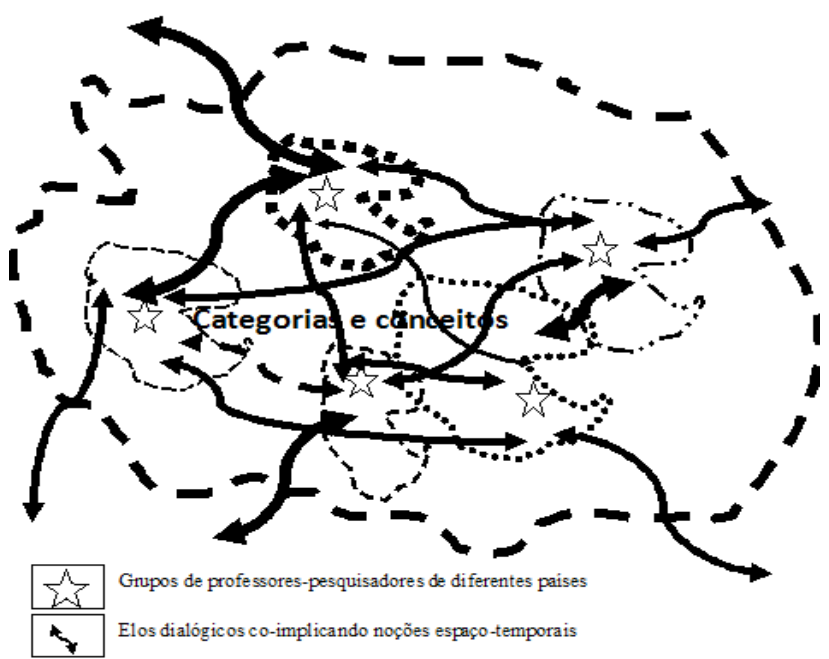

Fonte: Andreis e Ilgenfritz Toso, 2014.

Os elos teóricos supostos na rede são os conceitos e categorias geográficas, por isso tem lugar central na figura 1.0 contorno externo representa a composição da Redladgeo e as formas internas representam a composição dos diferentes grupos implicados, que constituem a rede. A imagem que elaboramos, embora seja complexa - porque é dialógica, ou seja, multiescalar, multidimensional e multireferencial- não é confusa, porque diálogo é sempre "confroencontro" (Andreis, 2014) aberto, provisório, inacabado, portanto, é irrepresentável, no qual sime-não são constitutivos, porque as singularidades são assumidas como componentes das possibilidades reflexivas prospectivas. Por isso, o marco dessa elaboração imagética é a dialógica, que "é a atividade do diálogo e atividade dinâmica do EU com o Outro em um território preciso socialmente organizado em interação linguística" (GEGe, 2009, p. 29). Nesse contexto de relações entre grupos do mesmo país e entre grupos de países latino-americanos, há laços fortes e estreitos e outros com menor proximidade, o que é um pressuposto de uma rede que se propõe ao fortalecimento do diálogo, no qual

O sujeito não se relaciona com o outro de modo funcional como um computador e um vendedor ou como um superior e um subordinado. [...] 0 relacionamento entre os sujeitos no diálogo é um relacionamento entre sujeitos integrais qualitativamente, cuja interação faz nascer uma nova (e terceira) qualidade, o "diálogo". A natureza dessa interação qualitativa pode ser entendida apenas no contexto da lógica dialética. (Bulavka e Busgalin, 2005, p. 6-7).

Os traçados das setas, que inferem as relações entre os diferentes grupos de pesquisa, são apresentados por meio de linhas contínuas (para suge- rir relação densa), que não se limitam a América Latina, pois há relações com outras regiões, especialmente, com países ibéricos. Essas relações inacabadas e inacabáveis da rede são apresentadas por setas que extrapolam o contorno Redladgeo. O contorno, que configura os diferentes grupos, é apresentado por meio de formas intermitentes, distintas entre si e não lineares. Laços dialógicos que aproximam diferenças e singularidades, cujos elos se encontram nas relações para pensar os processos de ensinar e aprender Ciências Humanas, especialmente Geografia, História e Ciências Sociais (Sociologia, História e Geografia ${ }^{6}$ ).

A Redladgeo compreende um contexto interessado em pensar sistematicamente, por isso resulta em elaborações que, entre outras, são publicadas na revista Anekumene ${ }^{7}$. Além disso, no encontro de 2014, assim como em outros, resultou na publicação de um livro, cujas reflexões, a seguir destacaremos.

\section{Escrevendo para melhor pensar}

Mario Osorio Marques (2008) enfatiza o processo de escrever como composição ao melhor pensar, porque pressupõe a interlocução sistemática de muitas vozes, que desafiam, agitando, conduzindo, animando e perturbando, permitindo e exigindo a atribuição de maior generalidade à singularidade do ou dos escreventes. Um espreitar fundamental à elaboração pautada em pressupostos, que envolvem vivências pessoais e profissionais em diálogo com referências teóricas (p. 27-29). Por isso, assumindo esse entendimento do escrever como movimento fundamental ao contexto acadêmico, apesar do encontro presencial -na forma de colóquio- priorize o debate, este é pautado em elaborações sistemáticas prévias e posteriores ao evento realizado bianualmente.

Considerando que os eixos temáticos do III colóquio, realizado em Buenos Aires em 2014, foram a política educativa e o desenvolvimento escolar, realizaram-se debates e produções que enfocaram o lugar da Geografia nos desenhos curriculares, com enfoque à formação inicial e continuada, e às práticas educativas e cotidiano escolar. Com base nessas temáticas, a obra elaborada, denominada Didáctica de la geografia: prácticas escolares y formación de profesores foi lançada no evento. Organizada pelas professoras María Victoria Fernández Caso e Raquel Gurevich e publicada pela editora Biblios de Buenos Aires, expressa dezessete capítulos, que estão organizados em três partes: Investigação didática e ensino de geografia na América Latina, Práticas docentes e formação profissional em geografia, e Saberes, experiências e valorações da geografia escolar.

6 Nos diferentes países da América Latina, a Geografia e História estão incluídas no currículo como Ciências Sociais.

7 Revista online disponível em: http://www.anekumene.com/index.php/revista. Acesso em: 27 out. 2014. 


\section{O Colóquio: a apresentação de uma produção escrita}

As pesquisas dos grupos, que confluem na Redladgeo, são investigações que resultam em enunciados dos sujeitos. São potentes influenciadores na constituição do currículo nas escolas e nas universidades, nos diferentes territórios. Isso pode ser percebido nas elaborações que privilegiam diferentes temáticas, que se transpassam no enfoque relacionado com o ensino da Geografia. Uma dialética-dialógica, que tem se complexificado, envolvendo sistematizações acerca do ensino e aprendizagem nas Ciências Sociais, com destaque para a formação cidadã, estudos sócio-territoriais até estudos das questões ambientais. Essas produções indiciam o fortalecimento da rede de investigação, mais necessário do que em qualquer outro tempo, pois se configura em espaço de diálogo, de construções e de formação inicial e continuada de professores. Para exemplificar esse complexo reflexivo da rede, a seguir, apresentamos algumas interpretações da obra lançada no evento.

Na primeira parte da obra, Investigación didáctica y enseñanza de la geografia en América Latina, encontram-se discussões com relação à caracterização do campo da didática como campo de investigação e que elementos tornam-se imprescindíveis nesse processo, além da Geografia enquanto ciência e a Geografia escolar. Incluem-se questionamentos sobre o que ensinamos, como ensinamos, porque ensinamos e quem são os sujeitos que participam desse processo de construção do conhecimento permeiam os textos dessa primeira parte. Nesse sentido, são reiteradas indagações como: Por quê os alunos não entendem e não aprendem o que para os professores pesquisadores parece tão óbvio? Por quê as aulas, muitas vezes, parecem sem sentido, sem importância? o que acontece com a formação de professores (inicial e continuada) nesse sentido? Como a construção da intelectualidade acontece? São interrogações feitas pelos pesquisadores, que perpassam o livro, e cujos textos a seguir apresentaremos.

O texto que abre a obra é Didáctica de la geografia: notas de investigación y problematización de las prácticas de enseñanza de María Victoria Fernández Caso e Raquel Gurevich e expõe o espaço como lugar praticado. As autoras propõem uma reflexão quanto ao lugar da Universidade tanto com relação às questões que envolvem a sociedade quanto como espaço fundamental no processo de formação de professores. Apresentam ainda as preocupações enfrentadas pelo grupo de professoras investigadoras do Departamento de Geografia e do Instituto de Geografia da Universidade de Buenos Aires. Nos proporcionam refletir sobre a necessidade de se sistematizar e socializar os conhecimentos produzidos acerca dos saberes em geografia. Apontam dentre essas preocupações questões como a formação de professores que historicamente buscava atender uma demanda específica do Estado, fortemente marcada pela influência jesuítica e posteriormente pela geografia crítica "desenvolvida" no Brasil. As autoras propõem ainda, a realização de reflexões em torno da didática da geografia e das ciências sociais como fundamental no processo de ensino e aprendizagem na busca por qualificação desse processo. Mostram ainda a influência dos grupos da Redladgeo tanto no processo de pesquisa quanto de discussões sobre a temática, bem como, da necessidade de continuar trabalhando com professores na tentativa de construir alternativas aos problemas enfrentados no ensino da geografia.

Enfoques geográficos, estrategias didácticas y formación ciudadana en Medellín (Colombia) y São Paulo (Brasil) de Alberto L. Gutiérrez Tamayo, Raquel Pulgarín y Sônia Maria Vanzella Castellar. É um texto no qual é apresentada a democracia como um projeto em construção, que requer uma sociedade civil forte, cidadania atuante e cidadãos formados. A cidade é entendida como expressão do construído e do vivido, como criação do homem; cenário das coisas e das relações humanas; nasce, desenvolve-se e visibiliza-se. Já os cidadãos são compreendidos como cidadãos territoriais, democráticos, participativos, sociais, políticos, ativos, críticos, arraigados fluidamente ao território. 0 enfoque refere que ao estudar a cidade, é preciso considerar o conhecimento do cotidiano e o conhecimento escolar, relacionado com as concepções de lugar, cidade, urbano e usos do solo. Para tanto, o texto propõe reflexões sobre Integração Curricular e interdisciplinariedade.

Helena Copetti Callai em Estudo do lugar e o livro didático no ensino e na aprendizagem da Geografia escreve que o estudo do lugar pode ser significativo para os sujeitos, pois é espaço de vida, é onde o cotidiano acontece. Apresenta discussões em torno das questões sobre o espaço absoluto considerado de forma linear, organizado via de regra como círculos concêntricos. A autora afirma que ao se trabalhar com o conceito de lugar e de cidade é preciso ter clareza desses conceitos, e apresenta a interrelação entre os espaços absoluto, relativo e relacional. Na análise acerca da relação com o livro didático, a pesquisadora, afirma que pode ser percebido como o condutor do ensino de geografia, em muitas realidades no Brasil. Isso, porque muitas vezes é utilizado como instrumento para conhecer o conteúdo; no planejamento das aulas; para propor atividades e organizar a avaliação. Nesse sentido, propõe que a geografia ensinada precisa considerar os conteúdos e conceitos de geografia; o saber da ciência e da disciplina e o conhecimento do aluno. Apresenta como desafios: a articulação entre o senso comum e o conhecimento científico e a reflexão a partir da força do lugar, como territórios de resistência, conhecendo o lugar, fazendo a reflexão.

Materiales curriculares para profesores de Geografía: contextos de producción y formas de uso de autoria de Viviana Zenobi, é resultado de estudos realizados desde 2008 na Universidad Nacional de Luján (Buenos Aires). Aborda uma investigação sobre como os professores de Geografia se vinculam com os materiais curriculares, que critérios utilizam ao selecionar recursos didáticos, além de centrar os estudos na produção dos materiais de geografia que são utilizados no processo de ensino e aprendizagem. O marco teórico que sustenta a pesquisa são a teoria interpretativa 
e crítica. A autora questiona porque os jovens professores, participantes da pesquisa, selecionaram certos materiais. A partir disso, a pesquisadora afirma compreender o docente como protagonista de suas práticas o que favorece a autonomia e a criatividade.

Encaminhando a finalização da primeira parte da obra, Andrea Coelho Lastória e Silvia Aparecida de Sousa Fernandes, são autoras do texto Avanços e desafios do ensino de geografia no Brasil: formação de professores e práticas escolares. Neste, apresentam frutos das pesquisas e reflexões que ocorrem no Grupo de Estudos da Localidade (ELO), sobre a Geografia Escolar e as alterações sofridas por ela no Brasil. Se propõe a discutir as concepções que os professores brasileiros de Educação Básica têm de Geografia e Geografia Escolar, além de buscar compreender o "lugar" da Geografia no currículo oficial da escola básica no Brasil e a possibilidade de alteração desse "lugar". Segundo as autoras o caminho pode ser os diálogos realizados nas comunidades de aprendizagem profissional da docência como o grupo elo que reúne professores, pesquisadores e alunos e, as redes internacionais de investigação sobre as questões curriculares.

A segunda parte da obra, Práticas docentes y formación profesional en geografia apresenta textos que refletem questões relativas a formação inicial e continuada de professores de ciências sociais em diferentes países. Retrata realidades vivenciadas por professores que ministram aulas principalmente nas disciplinas de Geografia e História, tendo em vista que na maioria dos países em que a Redladgeo atua não há separação entre essas áreas do conhecimento.

O primeiro texto, nessa segunda parte, é Aportes de la investigación em didáctica de la geografía a la formación docente: los casos de República Dominicana y Chile de autoria de Fabián Araya Palacio y Yudi Herrera Núñez. Este é um dos textos que tem como foco a investigação da Educação geográfica, principalmente no que tange ao desenvolvimento do pensamento espacial, que propicie o sentimento de pertencimento com os lugares aprendendo a compreende-los em sua complexidade. O texto analisa uma pesquisa que envolveu docentes do Chile e da República Dominicana. Apresenta como problema de investigação as estratégias didáticas utilizadas pelos professores desses dois países para desenvolver com seus alunos o desenvolvimento espacial sistêmico. Aponta ainda em suas conclusões, a relevância da educação geográfica, a importância dos projetos internacionais e do desenvolvimento do pensamento espacial.

As pesquisadoras Andrea Ajón, Lía Bachmann y Patricia Souto em El reto de enseñar problemas ambientales desde la complejidad: experiências en el marco de um proyeto de investigación-acción nos apresentam um projeto em que a temática desenvolvida foi a dos problemas ambientais, desenvolvidas em talleres de produção de sequências didáticas. 0 processo se configura numa investigação-ação, caracterizado pela experimentação e reflexão crítica. $O$ objeto central do projeto de pesquisa foi o ensino da geografia, com a problematização do ensino e questionamento de práticas vigentes, criando condições para que entre em cena o professor reflexivo.

La formación docente en Colombia y su incidencia en la enseñanza de la geografía é um texto assinado pelo Grupo Interinstitucional de Investigación Geopaideia. Compartilha conosco resultados e experiências dos programas de formação de professores, considerando o ensino da geografia, a compreensão do espaço geográfico, as relações espaço-temporais, a didática do meio urbano, além de pensar como o saber geográfico é abordado na escola. Aponta a integração das Ciências Sociais, principalmente da História e da Geografia na formação de professores na Colômbia, a experiência do grupo Geopaideia nesse processo, bem como, sobre o ensino da geografia com relação aos problemas de aprendizagem, construção de conhecimento social e formação do pensamento crítico, concepção e imagem de cidade, o lugar e a cidade no livro didático. Nesse sentido, estratégias didáticas são apresentadas e discutidas. Além disso, propõe pensar acerca de questões curriculares na busca do rompimento com práticas tradicionais do ensino da geografia.

Liliana Trigo, Analía Rotondaro, Natalia Flores y Andrés Flouch em seu texto Reflexión y acción en torno a la interculturalidad em el pensamento de profesores de Geografía que trabajan con alumnos de sectores populares de General Rodríguez, provincia de Buenos Aires, apresentam conclusões do projeto de pesquisa realizado em torno da diversidade cultural com classes de Geografia em nível secundário. Analisam a construção das representações dos professores, e posteriormente de suas alterações, com relação a diversidade cultural de seus alunos, pertencentes às camadas populares (sujeitos de aprendizagens). A pesquisa problematiza o que é considerado pelo professor no processo de construção do conhecimento, além de pensar na perspectiva da reflexão-ação como possibilidade de análise da prática docente dos professores envolvidos.

Concepciones geográficas de profesores de escuelas secundarias públicas de Paraná, Entre Ríos, é a elaboração de Alejandra Marek, Jacqueline Dalinger y Alejandra Anahí Laiker. Trata de uma sequência de projetos de pesquisas anteriores. Analisa as concepções epistemológicas utilizadas nas aulas dos professores. Para essa reflexão, consideram a prática áulica destes e seus planejamentos. Além disso, realizam entrevistas e observação das aulas. Essas são entendidas como possibilidades de mudanças no ensino de geografia, refletindo sobre as próprias práticas docentes. É uma pesquisa em andamento na qual são apresentadas as fases que ainda serão desenvolvidas posteriormente.

O texto que fecha a segunda parte é Formación de posgrado en didáctica de las ciencias sociales en la Universidad Nacional de la Patagonia San Juan Bosco de Sergio Merino. Apresenta-nos a possibilidade de refletir sobre os programas de formação de professores, das tensões e dificuldades que perpassam esse processo, além das reflexões acerca das pro- 
duções já realizadas na busca por escolhas teórico-metodológicas que permearão o trabalho dos pesquisadores iniciantes. Essas questões são constantes nesse complexo percurso desde o início. Propõe que é possível visualizar essa complexidade na constituição ou no desenvolvimento do profissional docente, desde o processo de elaboração de projetos de investigação exigindo tomadas de posição e decisões.

Na terceira parte são discutidos os Saberes, experiencias y valoraciones de la geografia escolar. Nesta encontramos relatos de pesquisa, bem como proposições com relação a geografia escolar. São experiências de pesquisas relatadas, comprometidas com o ensino da geografia, embora, como viemos afirmando, extrapolem esse campo do conhecimento.

É de autoria de Lana de Souza Cavalcanti o texto de abertura da última parte do livro. Intitula-se Formação básica, jovens cidadãos e conteúdos escolares: que lugar tem a cultura dos alunos no ensino de geografia? Inicia o processo reflexivo a partir de questões relativas aos interesses dos jovens. Debate como se articulam esses interesses ao que se acredita necessário ensinar na educação básica. Considera os conteúdos validados cientificamente com as demandas subjetivas dos alunos, principalmente por percebê-los como agentes da cidade, que tem relação com o espaço e o produzem, além de serem sujeitos participantes do processo de ensino e aprendizagem. A autora centra a discussão na questão da cidadania, pensando esses jovens e suas práticas cotidianas que não podem ser desconsideradas pela escola, além de sugerir temáticas e aspectos didáticos (orientações) para o ensino da geografia visando a formação cidadã.

O ensino de geografia física na educação básica: sobre a superação do obstáculo para a aprendizagem de Sônia Maria Vanzella Castellar y Julio Cesar Epifânio Machado, apresenta relatos de oficinas e trabalhos de campo em que se consideram os conhecimentos prévios dos alunos e são realizados estudos do meio físico com o intuito de construir conceitos. Apresenta o conceito de Obstáculo Epistemológico, com base em Bachelard apontando a influência deste no ato de conhecer, pois entendem que mantém o aluno dessa forma, preso a suas opiniões, sem estabelecer reflexões em torno do objeto. Ao propor o trabalho com as sequências didáticas, com atividades articuladas tendo com objetivo problematizar os conhecimentos prévios dos alunos, ocorre a contextualização do tema a partir de conceitos estudados e habilidades desenvolvidas, buscando assim, romper com a forma tradicional de se ensinar geografia.

Em Práticas educativas na geografia que se ensina na escola pública brasileira, Marcos Antônio Campos Couto apresenta um percurso do ensino público da geografia no Brasil, bem como, de sua precarização e as atuais políticas educacionais do país. Faz duras críticas à influência neoliberal na escola tornando-a mera instituição certificadora, à geografia muitas vezes ainda ensinada de forma enfadonha e descritiva, bem como expõe impasses teórico-metodológico da geografia e propostas de atividades pedagógicas desenvolvidas por alunos de graduação no Programa
Institucional de Bolsas de Iniciação à Docência (PIBID) da CAPES. Faz articulações entre a História da Educação no Brasil e o ensino da Geografia, as políticas de meritocracia como sendo extremamente excludentes e aponta a necessidade de se assumir um compromisso com as camadas menos privilegiadas da população.

Quésaben yqué quieren saber los estudiantes secundarios sobre problemas ambientales de Silvina Quintero, Mariana Saidón y Lía Bachmann indaga sobre a renovação temática da geografia na escola, principalmente com as que afetam a sociedade contemporânea. Este é o caso das questões ou dos problemas ambientais que apresentam uma demanda importante tanto das agendas sociais quanto das políticas atuais. Articula-se com a perspectiva dos sujeitos envolvidos na pesquisa que percebem a necessidade de se apropriar desses conhecimentos no intuito de que possam contribuir com a formação de futuros cidadãos. Além disso, propõem que várias são as temáticas que propiciam a articulação com diferentes áreas do conhecimento, extrapolando dessa forma a perspectiva geográfica, apesar desta apresentar grande identificação com os temas ambientais. Ao buscar as representações dos alunos sobre essas temáticas, abrem para a possibilidade de refletir sobre as práticas docentes e sobre os processos de ensino e aprendizagem. Apresentam resultados significativos sobre a visão dos alunos com relação ao tema ambiental na escola e com a necessidade de intervenções no trabalho até então realizado.

Lugares escondidos, identidades silenciadas: territórios em rede? de Jerusa Vilhena de Moraes y Jorge Luis Barcellos da Silva é o texto que encerra a terceira parte e a obra. Nele os autores relatam a experiência de uma pesquisa realizada ao longo de dois anos com alunos do curso de Pedagogia da Unifesp (Guarulhos, SP) no componente curricular Prática Pedagógica Programada (PPP) no qual apresentam experiências educativas desenvolvidas, principalmente as não escolares. Apresentam as concepções e representações atribuídos ao lugar em que viviam professores e alunos, considerando principalmente o bairro dos Pimentas em Guarulhos no qual está inserida a Universidade. 0 trabalho de pesquisa considerou desde conhecer as famílias que se relacionam com a escola do bairro, as concepções de infâncias, as condições socioeconômicas dessas famílias, as representações que estas possuíam com relação a instituição escolar. Uma das constatações apresentadas é a falta de conhecimento efetivo sobre os sujeitos envolvidos com a escola. A partir dessas constatações dentre tantas outras, propõem intervenções articulando conhecimentos geográficos da realidade vivenciada pelos alunos através do estudo do meio na busca de significar o que se estava estudando, privilegiando a construção de conceitos numa articulação principalmente com a História. Num outro momento, realizam entrevistas com gestores e professores da escola também coletando dados sobre as representações desses sujeitos a respeito do lugar em que está a escola e como isso reflete no processo de ensino e aprendizagem. Por fim, relatam a elaboração de um plano de ação por parte dos alunos das práticas pedagógicas programadas do curso de Pedagogia. 
Podemos inferir que os textos que constituem a obra enriquecem tanto o ensino quanto a pesquisa. Sua potência assenta-se no atravessamento da noção que discute a didática em Geografia, como rede que é tecida pelos elos construídos referenciados nos conceitos e categorias.

\section{A dialética-dialógica da rede}

Tanto a obra apresentada nesse ensaio quanto o III Colóquio realizado em Buenos Aires nos proporciona reflexões significativas relativas à didática da Geografia, o lugar dela nos currículos dos diferentes países que compõem a rede e a formação inicial e continuada dos professores. Quando fazemos referência a formação dos professores, não estamos apontando os "investigados" somente, mas um movimento quase antropológico de análise da própria professoralidade dos professores pesquisadores da Rede. Um movimento de tornar-se quase um nativo a partir do percurso investigativo.

A Rede composta por profissionais de diferentes países, com características étnicas e culturais distintas ao promover o Colóquio fortalece seu sentido, seu significado e sua forma, pensando num verdadeiro entrelaçamento entre a diversidade, mas também de pontos de encontro. Os professores-pesquisadores diretamente implicados na rede ao colocar em xeque não mais somente os sujeitos pesquisados, mas também suas próprias concepções, apontam que têm clareza quanto a responsabilidade e o compromisso ético que assumem tanto na formação de profissionais docentes, quanto na pesquisa e nas reflexões oriundas delas. Esses supostos reafirmam a ideia de que um galo sozinho não tece uma manhã, ele precisará sempre de outros galos, e que o amanhecer é sempre, também, anoitecer. Por isso, o hoje é ontem e também amanhã. Isso apresenta uma rede dialógica, aberta e relacional, inacabada e inacabável, disposta a questiona-se a si mesma.

\section{Referências bibliográficas}

Andreis, A. M. (2014). Cotidiano: uma categoria geográfica para ensinar e aprender na escola. Tese (Doutorado em Educação nas Ciências: concentração Geografia), Programa de Pós-Graduação em Educação nas Ciências, Universidade Regional do Noroeste do Estado do Rio Grande do Sul - Unijuí, ljuí/RS.

Bulavka, L.; Buzgalin, A. (2005). Os próximos cem anos de Mikhail Bakhtin: a dialética do diálogo versus a metafísica do pós-modernismo. Novos Rumos, 20. 44, 4-14. Disponível em: http://www2.marilia. unesp.br/revistas/index.php/novosrumos/article/view/2130 Acesso em: 25 abr. 2013.

Fernández Caso, M. V.; Gurevich, R. (2014). Didáctica de la geografia: prácticas escolares formación de profesores. Ciudad Autónoma de Buenos Aires: Biblos.

Grupo de Estudos Dos Generos do Discurso (GEGe). (2009). Palavras e contrapalavras: glossariando conceitos, categorias e noções e de Bakhtin. Caderno de estudos I para iniciantes. São Carlos: Pedro e João editores.

Marques, M. O. (2008). Escrever é preciso: o princípio da pesquisa. Petrópolis: Vozes. 